\title{
Nuance need not be subtle
}

\author{
Joseph S. Coselli, MD
}

\author{
From the Division of Cardiothoracic Surgery, Michael E. DeBakey Department of Surgery, Baylor College of \\ Medicine; and the Section of Adult Cardiac Service, Texas Heart Institute, CHI St. Luke's Health-Baylor \\ St. Luke's Medical Center, Houston, Tex. \\ Disclosures: Author has nothing to disclose with regard to commercial support. \\ Received for publication Nov 7, 2016; accepted for publication Nov 8, 2016; available ahead of print Dec 7, 2016. \\ Address for reprints: Joseph S. Coselli, MD, One Baylor Plaza, BCM 390, Houston, TX 77030 (E-mail: jcoselli@ \\ bcm.edu). \\ J Thorac Cardiovasc Surg 2017;153:e43-4 \\ $0022-5223 / \$ 36.00$ \\ Copyright (C) 2016 by The American Association for Thoracic Surgery \\ http://dx.doi.org/10.1016/j.jtcvs.2016.11.019
}

In this issue of The Journal of Thoracic and Cardiovascular Surgery, Levack and colleagues ${ }^{1}$ at the Heart and Vascular Institute of the Cleveland Clinic, describe a 61-year-old male patient who had undergone open graft replacement of the ascending aorta and lesser curvature of the aortic arch (ie, hemiarch) for an acute DeBakey type I aortic dissection roughly 20 years previously. Subsequently, nearly a decade ago, he underwent thoracic endovascular aortic repair to treat a portion of his residual chronic distal aortic dissection. With time, an extensive $8.5-\mathrm{cm}$ thoracoabdominal aortic aneurysm developed, involving the segment of the aorta that was not covered by the stent graft: the lower descending thoracic aorta extending to the aortic bifurcation and common iliac arteries. Importantly, a preoperative review of computed tomographic (CT) imaging identified a duplicate inferior vena cava (IVC), with the left side substantially larger than the right. The aneurysm was opened and anatomically reconstructed with a Dacron polyester fabric graft. The duplicate IVC was managed intraoperatively by mobilizing the left-sided IVC and tunneling the replacement graft into its proper anatomic location underneath the IVC.

Open thoracoabdominal aneurysm surgery performed at institutions dedicated to this procedure can be carried out successfully with modest morbidity and mortality. ${ }^{2-5}$ In this case report, Levack and colleagues ${ }^{1}$ point out the importance of careful review of preoperative CT scanning to identify possible anatomic anomalies. In part, this is a reflection of the transition from the past use of routine preoperative arteriography to the contemporary use of CT angiography scanning and magnetic resonance angiography scanning to aid preoperative diagnosis and planning of open therapeutic repair. Importantly, CT scanning has the advantage of providing all the information that would be available on arteriography as well as the ability to identify anatomic anomalies such as described in this article. Levack and colleagues ${ }^{1}$ rightfully point out the options that are available when encountering a left-sided IVC. These include cannulation of the left IVC should division of its

\section{References}

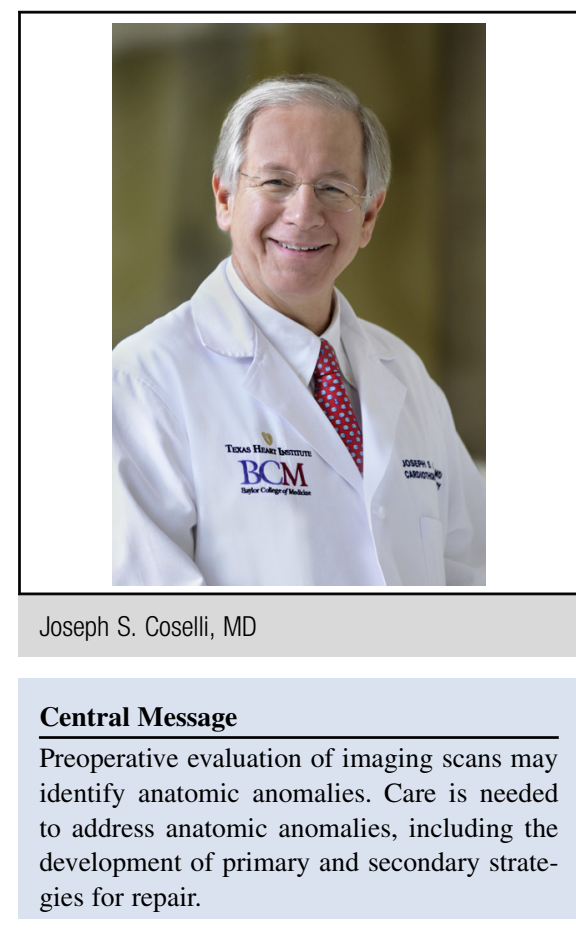

See Article page e39.

crossing of the aneurysm be necessary. In addition, if the graft reconstruction is better positioned to the left-sided IVC, then naturally it would be the option of choice. If the left-sided IVC is relatively small, reconstruction may not be necessary. If, however, as in this case described by Levack and colleagues, ${ }^{1}$ the IVC is large and would need to be divided, reconstruction after completion of the aortic aneurysm repair would certainly be appropriate.

The importance of this article lies not in the specific operative techniques applied but rather in the importance of careful preoperative evaluation that includes a strategy to identify possible anatomic anomalies. Moreover, careful operative planning is needed to address anatomic anomalies, including the development of both a primary strategy and alternate secondary options that may be needed to be immediately called on at the time of open reconstruction.

1. Levack MM, Keshavamurthy S, Schoenhagen MD, Johnston DR. Management of a duplicated inferior vena cava in thoracoabdominal aortic aneurysm repair. J Thorac Cardiovasc Surg. 2017;153:e39-41.

2. Coselli JS, LeMaire SA, Preventza O, de la Cruz KI, Cooley DA, Price MD, et al Outcomes of 3309 thoracoabdominal aortic aneurysm repairs. J Thorac Cardiovasc Surg. 2016;151:1323-37.

3. Kouchoukos NT, Kulik A, Castner CF. Open thoracoabdominal aortic repair for chronic type B dissection. J Thorac Cardiovasc Surg. 2015;149(2 Suppl):S125-9. 
4. Gaudino M, Lau C, Munjal M, Girardi LN. Open repair of ruptured descending thoracic and thoracoabdominal aortic aneurysms. J Thorac Cardiovasc Surg. 2015; 150:814-21.
5. Kimura N, Itoh S, Yuri K, Adachi K, Matsumoto H, Yamaguchi A, et al. Reoperation for enlargement of the distal aorta after initial surgery for acute type A aortic dissection. J Thorac Cardiovasc Surg. 2015;149(2 Suppl):S91-8. 